\title{
Commentary \\ Too much of a good thing: the curse of overfeeding
}

Richard D Griffiths

Division of Metabolic \& Cellular Medicine, School of Clinical Sciences, University of Liverpool, Liverpool, L69 3GA, UK

Corresponding author: Richard D Griffiths, rdg@liverpool.ac.uk

Published: 9 November 2007

Critical Care 2007, 11:176 (doi:10.1186/cc6165)

This article is online at http://ccforum.com/content/11/6/176

(c) 2007 BioMed Central Ltd

See related research by Dissanaike et al., http://ccforum.com/content/11/5/R114

\begin{abstract}
Enteral nutrition (EN) gives a legacy of under nutrition in intensive care patients but few appreciate that parenteral nutrition (PN) carries the other risk of overfeeding if used injudiciously. Overfeeding presents a significant metabolic stress but tight glycaemic control is now masking the traditional warning signs and does not on its own negate the need to give patients the right amount at the right time.
\end{abstract}

Natural selection has refined our ability to handle acute infection and short-term starvation but has not prepared us for the excesses of modern life and intensive care practice. There are two key lessons from the observational study by Dissanaike and co-workers [1] who have studied parenterally fed patients in the era of tight glycaemic control. Firstly, parenteral nutrition (PN) as practiced by intensive care doctors can result in serious overfeeding and secondly this overfeeding impacts on infectious morbidity. The title unfortunately does not address the more serious issue of overfeeding that occurs when this route of nutrition delivery is abused. Of course this perpetuates the misguided view that it is PN that is a "poison" [2] rather than the real issue of overfeeding.

As a warning about overfeeding the authors are to be commended in exposing a rampant neglect of care that I am sure is common across all but the most ardently nutrition focussed intensive care units. It is obvious that parenteral nutrition lends itself to inappropriate overfeeding just as enteral nutrition (EN) is usually characterised by underfeeding. Few appear to appreciate the extent to which additional calories are administered intravenously. The principle outcome observed of increased blood stream infections is only an association with overfeeding and in an observational study cannot be causally linked. Interestingly there appeared no association with increased mortality.

\section{Why then should there be a link between nutritional excess and infection?}

The principle calorie substrates of glucose and lipids have well defined rates of utilisation and storage. When not given in excess they are handled in a wide range of proportions in the critically ill and septic patient [3] but whether given by either the enteral or parenteral route because of insulin resistance do not have the same metabolic consequences as in the well state [4]. However overfeeding of either fats or glucose stresses the metabolic tolerance and compounds the impairment of storage associated with insulin resistance. Obesity and the metabolic syndrome is the chronic equivalent state, intimately linked with inflammation and complex signalling interactions [5].

Critical to evolutionary survival has been our ability to withstand starvation and our capacity to mount an inflammatory response to pathogens [6]. We therefore have a signalling system that closely links nutrition sensing, storage and inflammation and it should be of no surprise that our liver and adipose tissues have an architectural organisation in which metabolic cells are in close proximity to immune cells (Kupffer cells and macrophages respectively). Indeed this interface and signalling is believed to be behind the development of metabolic disease and inflammation in obesity and diabetes [7]. Interestingly the lowly Drosophila has only one structure, a fat body that efficiently combines the immune, adipose cell and hepatic cell functions in one organ system [8]. This provides a configuration that enables close integrated communication (and in man also with skeletal muscle) and ensures the right nutrient provision to mount the inflammatory response. However it did not evolve in the context of continuous nutrient delivery, nor I suspect with sustained immobility! The endoplasmic reticulum (ER) and the signal interaction on this complex structure are particularly sensitive to nutrient signalling and are the focus of much metabolic

$\mathrm{EN}=$ enteral nutrition; $\mathrm{ER}=$ endoplasmic reticulum; ICU = intensive care unit; NICE $=$ National Institute for Health and Clinical Excellence; PN $=$ parenteral nutrition. 
research [5]. Evidence suggests that with substrate excess there are metabolically induced increased oxidative processes, increased reactive oxygen species, and increased storage challenges carrying consequences for ER stress signalling through the major inflammatory pathways. It is a reasonable hypothesis that nutritional excess in intensive care unit (ICU) patients confounds many aspects of immune function and increases the oxidative load.

\section{So what does this mean for clinical practice?}

This debate has little to do with the route of nutrition but everything to do with the content and amount of nutrition. In intensive care modern PN does not carry increased risk [9]; indeed the EN $\vee$ PN debate was recognised as futile by the UK Nutrition guidelines published by the National Institute for Health and Clinical Excellence (NICE) [10]. This emphasised a stepwise progression moving from oral to the more invasive enteral and parenteral approaches based upon need and risk but also cautioned about excess and avoidance of the refeeding syndromes.

Based upon observational evidence that outcome is better in those fed only two-thirds of their "requirements" [11] an oft quoted argument is that it is "safer" to give hypocaloric feeding. However the observation could be showing that it is easier to overfeed the sicker and poorer outcome patients in whom it might be more critical to have properly matched delivery to their requirements. Hypocaloric feeding only exacerbates the calorie deficit that has a legacy in the long term [12]. Perhaps getting it right by improving our measurements is needed [13].

\section{Can we generalise upon these observations?}

The study used a multiple infusion PN and infused substrates at different times that might have increased metabolic stress; and the absence of glutamine in the amino acid solutions may have contributed to infectious morbidity risk and outcome [14]. The final concern is that in the era of tight glycaemic control clinicians could be masked from the signs of overfeeding. Hyperglycaemia in the past would have resulted in a reduction in the feed delivery, although avoiding hyperglycaemia insulin therapy will simply facilitate the metabolic stress if overfeeding is not avoided. Lack of attention to nutrition detail may be why the second round of multi-centre studies (as yet unpublished) are finding it hard to replicate the pioneering single centre studies (by Professor Greet Van den Berghe and colleagues in Leuven, Belgium). Her studies received criticism because of the use of parenteral delivery but a recent paper [15] tabulates the nutrition delivery and shows neither under delivery nor overfeeding with total mean daily kilocalorie intakes ranging between 15 and $25 \mathrm{kcal} / \mathrm{kg} /$ day. Be warned you can have too much of a good thing.

\section{Competing interests}

RDG has received small research project grants from Fresenius Kabi (not within the last 2 years) and occasional travel expenses to speak at international conferences. He has no direct association with any commercial company.

\section{References}

1. Dissanaike S, Shelton M, Warner K, O'Keefe GE: The risk for bloodstream infections is associated with increased parenteral caloric intake in patients receiving parenteral nutrition. Critical Care 2007, 11:R114.

2. Marik PE, Pinsky M: Death by parenteral nutrition. Intensive Care Med 2003, 29:867-869.

3. Tappy L, Schwarz JM, Schneiter P, Cayeux C, Revelly JP, Fagerquist CK, Jequier E, Chiolero R: Effects of isoenergetic glucose-based or lipid-based parenteral nutrition on glucose metabolism, de novo lipogenesis, and respiratory gas exchanges in critically ill patients. Crit Care Med 1998, 26: 860-867.

4. Tappy L, Berger M, Schwarz JM, McCamish M, Revelly JP, Schneiter $\mathrm{P}$, Jequier E, Chiolero R: Hepatic and peripheral glucose metabolism in intensive care patients receiving continuous high- or low-carbohydrate enteral nutrition. JPEN J Parenter Enteral Nutr 1999, 23:260-267.

5. Hotamisligil GS: Inflammation and metabolic disorders. Nature 2006, 444:860-867.

6. Levin BR, Lipsitch M, Bonhoeffer S: Population biology, evolution, and infectious disease: convergence and synthesis. Science 1999, 283:806-809.

7. Shoelson SE, Lee J, Goldfine $A B$ : Inflammation and insulin resistance. J Clin Invest 2006, 116:1793-1801.

8. Sondergaard L: Homology between mammalian liver and the Drosophila fat body. Trends Genet 1993, 9:193.

9. Griffiths RD: Is parenteral nutrition really that risky in the intensive care unit? Curr Opin Clin Nutr Metab Care 2004, 7: $175-81$.

10. National Institute for Health and Clinical Excellence: Nutrition Support in adults [www.nice.org.uk/CG032].

11. Krishnan JA, Parce PB, Martinez A, Diette GB, Brower RG: Caloric intake in medical ICU patients: consistency of care with guidelines and relationship to clinical outcomes. Chest 2003, 124:297-305.

12. Berger MM, Chiolero RL: Hypocaloric feeding: pros and cons. Curr Opin Crit Care 2007, 13:180-186.

13. Dvir D, Cohen J, Singer P: Computerised energy balance and complications in critically ill patients: an observational study. Clin Nutr 2006, 25:37-44.

14. Bongers T, Griffiths RD, McArdle A: Exogneous glutamine; the clinical evidence. Crit Care Med 2007, 35(9 Suppl):S545S552.

15. Van den Berghe G, Wilmer A, Milants I, Wouters PJ, Bouckaert B, Bruyninckx F, Bouillon R, Schetz: Intensive insulin therapy in mixed medical/surgical intensive care unit: Benefits versus harm. Diabetes 2006, 55:3151-3159. 